\title{
COVID-19: The Importance of Sleep
}

\author{
Jonathan Sunkersing ${ }^{1}$ and David Sunkersing ${ }^{2 *}$ \\ ${ }^{1}$ Nuffield Department of Clinical Neurosciences, University of Oxford, Oxford, UK \\ ${ }^{2}$ Faculty of Medicine, Imperial College London, London, UK
}

Presently, much of the world's media and social focus is, understandably, dominated by the COVID-19 pandemic. With the backdrop of high-speed developments and the evolving global situation, we are all experiencing changes to daily routines, social and financial infrastructures - and direct health consequences due to the virus. These changes can often be accompanied by increased stress and fear. Importantly, the impact on sleep is a pressing public health concern $[1,2]$.

A wealth of evidence demonstrates the negative effects of poor sleep on health ranging from increased risks of hypertension, type 2 diabetes, depression, anxiety $[3,4]$ and direct impacts on the immune system [5]. Additionally, we know that a proportion of those with acute sleep problems may develop chronic sleep problems [6].

Our knowledge of COVID-19 and sleep is constantly evolving as data and studies are regularly published. COVID-19 has resulted in a significant increase in insomnia prevalence, mental health problems and sleep disturbance [7-9]. The virus has also profoundly impacted the way we treat and diagnose existing sleep problems [10] particularly with sleep related breathing disorders [11]. The considerable overlap with risk factors and co-morbidities for obstructive sleep apnoea and poor outcome with COVID-19 suggests that addressing these sleep problems may also reduce the mortality from the virus.

Despite this knowledge, we still do not understand several facets of sleep and COVID-19. Ignoring the acute and chronic sleep problems during this pandemic would be indefensible given the accumulating evidence. Further, there is sparse data regarding the long-term impacts of COVID-19 on sleep. Does COVID-19 have long term impacts on sleep? Does it affect breathing at night and so affect our sleep at night in previously healthy? The studies on sleep related breathing disorders and COVID-19 seem to illustrate complex a relationship and studies may help us optimise patient care to this vulnerable group.

Current recommendations are mainly based on pre-existing evidence for the treatment of sleep disorders [12]. However, with further knowledge, we may be able to refine our strategies and for different population groups. In addition, we may find that sleep has a direct impact on the course of the virus itself, given how sleep and immune function work in tandem.

Further, high quality studies are required to enhance our insight into the treatment and prevention of sleep problems during this time. We eagerly await the results of large, high quality studies, such as the International COVID-19 Sleep Study, which may provide answers to some of these questions and help guide future treatment. We should

Copyright: (C2020 Sunkersing J. This is an open-access article distributed under the terms of the Creative Commons Attribution License, which permits unrestricted use, distribution, and reproduction in any medium, provided the original author and source are credited. encourage health policy makers to seriously consider the role sleep has to play in society at this time.

\section{Conflicts of Interest}

The authors declare no potential conflicts of interest with respect to the research, authorship, and/or publication of this article.

\section{Funding}

The authors received no financial support for the research, authorship, and/or publication of this article.

\section{References}

1. Becker PM (2020) Sleep during times of coronavirus: early Chinese experience. Sleep Med 11: S1389-9457. [Crossref]

2. Wang W, Song W, Xia Z, He Y, Tang L, et al. (2020) Sleep Disturbance and Psychological Profiles of Medical Staff and Non-Medical Staff During the Early Outbreak of COVID-19 in Hubei Province, China. Front Psychiatry 11: 733. [Crossref]

3. Mayers A, Grabau E, Campbell C, Baldwin D (2009) Subjective sleep, depression and anxiety: inter-relationships in a non-clinical sample. Hum Psychopharmacol 24: 495501. [Crossref]

4. Huang Y, Zhao N (2020) Generalized anxiety disorder, depressive symptoms and sleep quality during COVID-19 outbreak in China: a web-based cross-sectional survey. Psychiatry Res 288: 112954. [Crossref]

5. Besedovsky L, Lange T, Haack M (2019) The Sleep-Immune Crosstalk in Health and Disease. Physiol Rev 99: 1325-1380. [Crossref]

6. Morin CM, Carrier J (2020) The acute effects of the COVID-19 pandemic on insomnia and psychological symptoms. Sleep Med 6: S1389-9457. [Crossref]

7. Gualano MR, Lo Moro G, Voglino G, Bert F, Siliquini R (2020) Effects of Covid-19 Lockdown on Mental Health and Sleep Disturbances in Italy. Int J Environ Res Public Health 17: 4779. [Crossref]

8. Fu W, Wang C, Zou L (2020) Psychological health, sleep quality, and coping styles to stress facing the COVID-19 in Wuhan, China. Transl Psychiatry 10: 225.

9. Lin LY, Wang J, Ou-Yang XY, Miao Q, Chen R, et al. (2020) The immediate impact of the 2019 novel coronavirus (COVID-19) outbreak on subjective sleep status. Sleep Med 1: S1389-9457. [Crossref]

10. Grote L, McNicholas WT, Hedner J \& ESADA collaborators (2020). Sleep apnoea management in Europe during the COVID-19 pandemic: data from the European Sleep Apnoea Database (ESADA). Eur Respir J 55: 2001323. [Crossref]

11. Miller M, Cappuccio F (2020) A systematic review of COVID-19 and obstructive sleep apnoea. Sleep Medicine Reviews 55: 101382.

12. Altena E, Baglioni C, Espie CA, Ellis J, Gavriloff D, et al. (2020) Dealing with sleep problems during home confinement due to the COVID-19 outbreak: Practical recommendations from a task force of the European CBT-I Academy. J Sleep Res 4 e13052. [Crossref]

${ }^{\star}$ Correspondence to: David Sunkersing, Faculty of Medicine, Imperial College London, London, UK, E-mail: d.sunkersing@imperial.ac.uk

Received: October 13, 2020; Accepted: October 20, 2020; Published: October 23,2020 